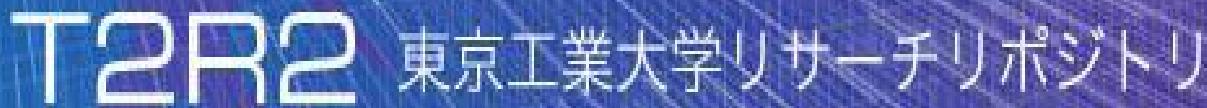

\section{Tokyo Tech Research Repository}

\section{論文 /著書情報 \\ Article /Book Information}

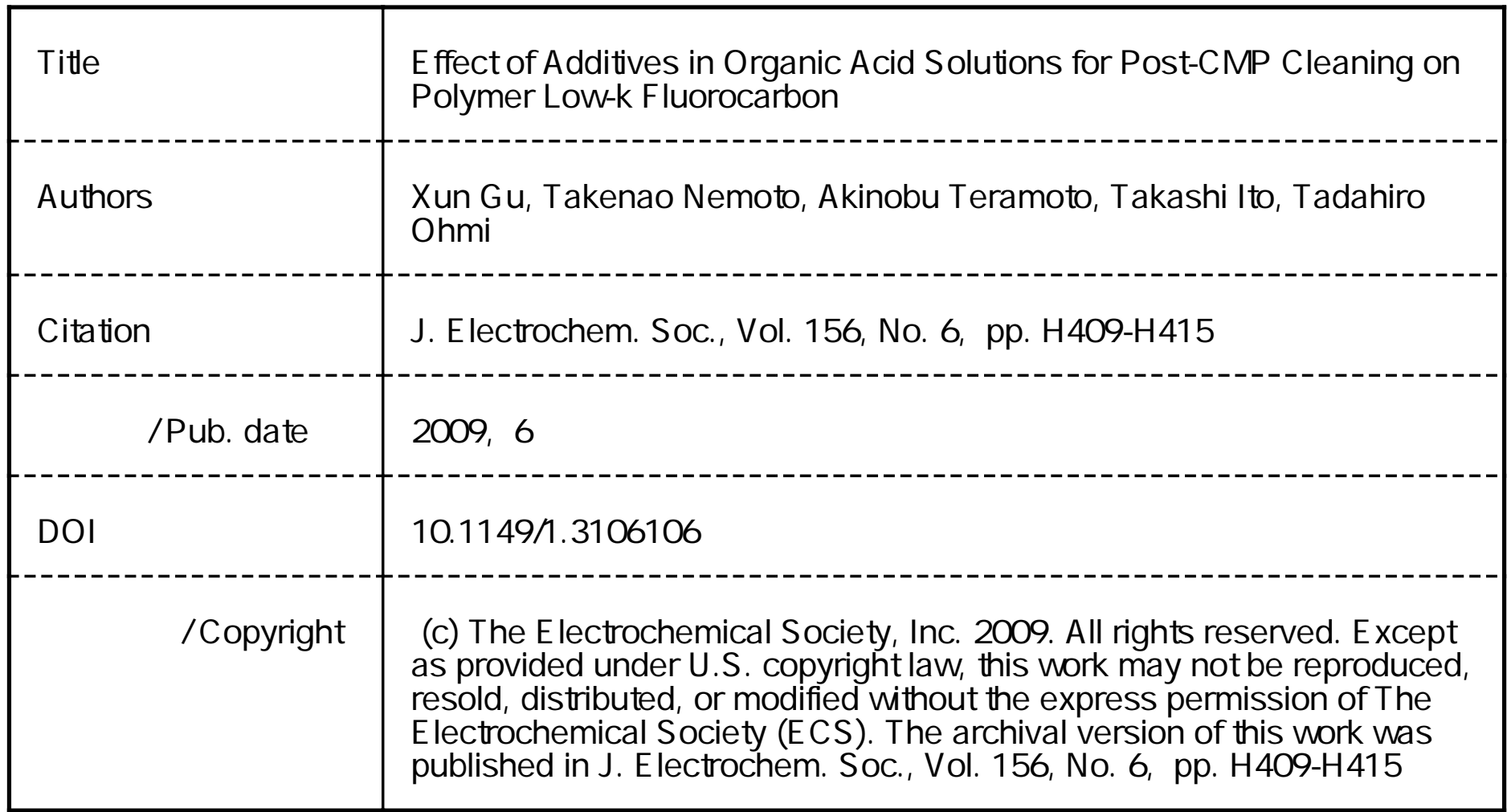




\title{
Effect of Additives in Organic Acid Solutions for Post-CMP Cleaning on Polymer Low- $k$ Fluorocarbon
}

\author{
Xun Gu, ${ }^{\mathrm{a}, \mathrm{z}}$ Takenao Nemoto, ${ }^{\mathrm{b}}$ Akinobu Teramoto, ${ }^{\mathrm{b}, *}$ Takashi Ito, ${ }^{\mathrm{a}}$ and \\ Tadahiro Ohmi ${ }^{\mathbf{b}, \mathbf{c}, *}$ \\ ${ }^{a}$ Graduate School of Engineering, Tohoku University, Aramaki, Aoba-ku, Sendai 980-8579, Japan \\ ${ }^{b}$ New Industry Creation Hatchery Center, Tohoku University, Japan \\ ${ }^{c}$ World Premier International Research Center, Tohoku University, Japan
}

The appropriate post- chemical mechanical polishing (CMP) cleaning solution for an advanced nonporous polymer, ultralow- $k$ fluorocarbon film is proposed. While decrease in fluorine content measured by high-resolution X-ray photoelectron spectroscopy and increase in dielectric constant were observed after additives cleaning with oxalic acid, no significant change of fluorine content and dielectric constant were found after citric acid with different additives and acids without additives cleanings. This reveals that additives play an important role in degradation of the fluorocarbon film. An appropriate selection of additives is important to clean the fluorocarbon film in post-CMP cleaning in advanced large-scale integrated generations. To complete successful integration of the post-CMP cleaning on new dielectric materials such as nonporous low- $k$ fluorocarbon film, an appropriate solution and additives should be carefully selected to avoid electrical degradation in subsequent process.

(C) 2009 The Electrochemical Society. [DOI: 10.1149/1.3106106] All rights reserved.

Manuscript submitted November 24, 2008; revised manuscript received February 3, 2009. Published April 1, 2009.

As technology node progresses, low- $k$ dielectrics have been developed to reduce resistance-capacitance delay in large-scale integrated (LSI) circuits. Porous materials are being implemented as an ultralow- $k$ dielectric for advanced LSI devices. It is reported that introduction of these porous low- $k$ films in LSI fabrication brings difficulties and complexities due to their porous structure. ${ }^{1-12}$ For example, delamination is reported to occur when copper on porous low- $k$ dielectric is polished by chemical mechanical polishing (CMP) ${ }^{6-10}$ Moreover, increase of dielectric constant is found when porous low- $k$ dielectric is patterned by a dry etching process. ${ }^{11,12}$ Alternative nonporous polymer fluorocarbon is considered an indispensable ultralow- $k$ dielectric to avoid such complexity for LSI fabrication. ${ }^{13-15}$

Microwave excited plasma using the radial line slot antenna with a dual-shower-plate structure reactor was developed to achieve a very low electron temperature (around $1-2 \mathrm{eV}$ ). ${ }^{1-18}$ In this new reactor, the deposited gases are supplied by a lower shower plate inserted in the diffusion plasma region. ${ }^{13,15}$ The fluorocarbon film formed using the new reactor indicates not only a low dielectric constant but also low leakage current density, sufficient mechanical strength, strong adhesion, and good surface smoothness. ${ }^{15}$ Therefore, the nonporous fluorocarbon film is proposed as the foreground ultralow- $k$ film in advanced LSI devices. Although the fluorocarbon film is expected to be stable for its structural advantage, a damageless process is anticipated to avoid dielectric constants change in subsequent process steps. A low-damage physical vapor deposition process was applied to reduce damage on the fluorocarbon. ${ }^{19}$ The CMP and post-CMP processes are also of concern with regard to damage.

In the cleaning process for devices of the $100 \mathrm{~nm}$ node and beyond, an ultraclean surface must be achieved without using strong chemical or mechanical forces. ${ }^{20} \mathrm{~A}$ key solution to prevent contaminant redeposition is to make the best use of trace additives such as a chelating agent and a surfactant. ${ }^{20}$ In this study, the effects of postCMP cleaning additives on the chemical structure and electrical properties of fluorocarbon are evaluated.

\section{Experimental}

Fluorocarbon films $160 \mathrm{~nm}$ thick were deposited on silicon substrates by using a mixture of $\mathrm{C}_{5} \mathrm{~F}_{8}$ and Ar gases. ${ }^{13,15}$ The oxalic acid $\left(\mathrm{C}_{2} \mathrm{H}_{2} \mathrm{O}_{4}\right)$ with additive A [product name: CMP-M05/203 (Kanto Chemical Co., Inc.)] was chosen as a first candidate because it is

* Electrochemical Society Active Member

z E-mail: guxun@fff.niche.tohoku.ac.jp widely used for post-CMP cleaning on $\mathrm{Cu}$ in porous $\mathrm{SiCOH}$ low- $k$ dielectrics due to its low $\mathrm{Cu}$ corrosion. ${ }^{21}$ Moreover, a citric acid $\left(\mathrm{C}_{6} \mathrm{H}_{8} \mathrm{O}_{7}\right)$ with different additive $\mathrm{B}$ [product name: CLEAN-100 (Wako Pure Chemical Industries, Ltd.)] was chosen as an alternative novel post-CMP cleaning solution. Both solutions were diluted by 30 times by ultrapure water, and $\mathrm{pH}$ values for both diluted solutions were controlled at 2.2. The fluorocarbon films were dipped in a CMP slurry of tantalum (Ta) [product name: HS-T815-B1 (Hitachi Chemical Co., Inc.)] for $1 \mathrm{~min}$ to expose silica particles in the slurry. Scanning electron microscopy (SEM) images and particle counts indicate that wafers dipped into the slurry exhibit similar surface contamination characteristics as those of polished wafers using same slurry. They were cleaned by a brush scrubber with a soft polyvinyl alcohol brush produced by Entegris, Inc., at a $300 \mathrm{rpm}$ brush rotation rate and $150 \mathrm{rpm}$ wafer rotation rate for $1 \mathrm{~min}$ with solutions.

Chemical bonding structures in the fluorocarbon films before immersion were obtained by the Fourier transform infrared/attenuated total reflection (FTIR/ATR). C 1s photoelectron spectra were measured with high-resolution X-ray photoelectron spectroscopy (XPS) (ESCA-300, which is a highly sensitive and high-resolution photoelectron spectrometer equipped with a monochromatic $\mathrm{Al} \mathrm{K} \alpha$ radiation source) to obtain chemical structures of the fluorocarbon film. ${ }^{22}$ This tool was equipped with a larger X-ray power supply $(8 \mathrm{~kW})$ and larger energy analyzer diameter to achieve high resolution $(250 \mathrm{meV})$. A sample stage rotation movement mechanism participates in measurement at different photoelectron detection take-off angles to detect either surface signals or bulk ones. Tiny components in desorbed species on the fluorocarbon surface were detected by thermal desorption spectroscopy (TDS), and the molecular atoms were detected by atmospheric pressure ionization mass spectroscopy. After immersion a fluorocarbon film was placed in a vacuum chamber with continuous Ar purge flow and kept at 300 and $400{ }^{\circ} \mathrm{C}$ to measure degassing species. To prevent deposition of particles in solution, it is very important to control the zeta-potential of the substrate surface and particles to the same polarity. ${ }^{23}$ Zeta potentials of solutions were measured through electrophoresis on the Otsuka Electronics ELSZ-2. Wettability of the particles and substrate surface is another important parameter. ${ }^{23}$ Surface wettability was measured through the contact angle of a droplet dropped onto the wafer surface. The number of residue particles was counted by the KLATencor Surfscan 6420 down to a $0.16 \mu \mathrm{m}$ size after cleaning. Dielectric constants on the fluorocarbon films before and after immersion or brush cleaning were measured by the $\mathrm{Hg}$-probe capacitancevoltage $(C-V)$ measurement at a frequency of $1 \mathrm{MHz}$ by a Four Dimension, Inc., $C-V$ map.

$\mathrm{Cu} 1 \mu \mathrm{m}$ thick on seed $\mathrm{Cu} / \mathrm{Ta}$ were prepared by electroplating 


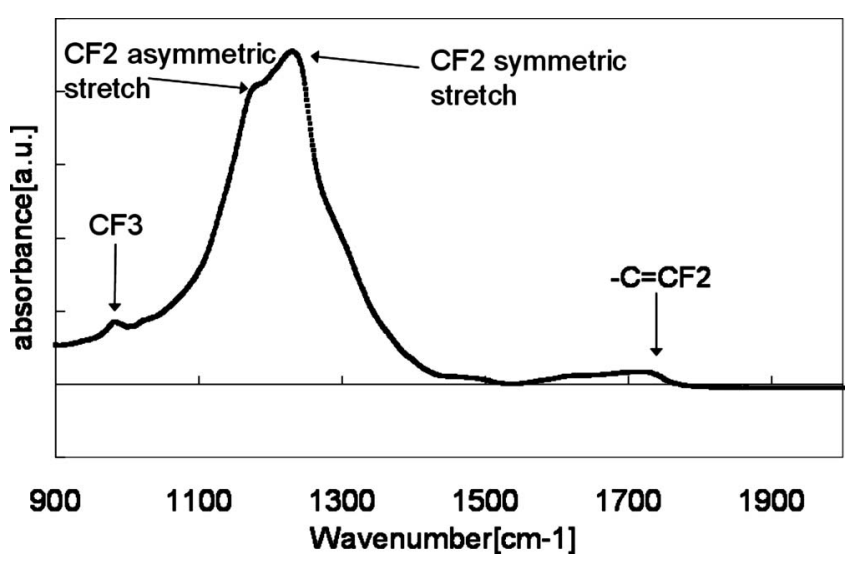

Figure 1. FTIR/ATR spectra for chemical-bonding structure of fluorocarbon films before immersion.

using SEM to evaluate thickness changes after immersion. Conventional single damascene $\mathrm{Cu}$ lines with silicon dioxide were also prepared to evaluate corrosion by the optical microscope.

\section{Results and Discussion}

Analysis of fuorocarbon film.- Chemical bonding structures of the fluorocarbon film were measured by FTIR/ATR, as shown in Fig. 1. Wavenumber values of carbon $(\mathrm{C})$ interacting with fluorine (F) have been reported as $-\mathrm{C}=\mathrm{CF}_{2}$ bond, $\mathrm{CF}_{2}$ asymmetric stretch bond, $\mathrm{CF}_{2}$ symmetric stretch bond, and $\mathrm{CF}_{3}$ bond at 1720,1220 , 1160 , and $975 \mathrm{~cm}^{-1}$, respectively. ${ }^{24}$ Figure 2 shows $\mathrm{C} 1 \mathrm{~s}$ spectra of the fluorocarbon film measured by high-resolution XPS at take-off angles (measured from the normal to sample surface) of (a) 90 and
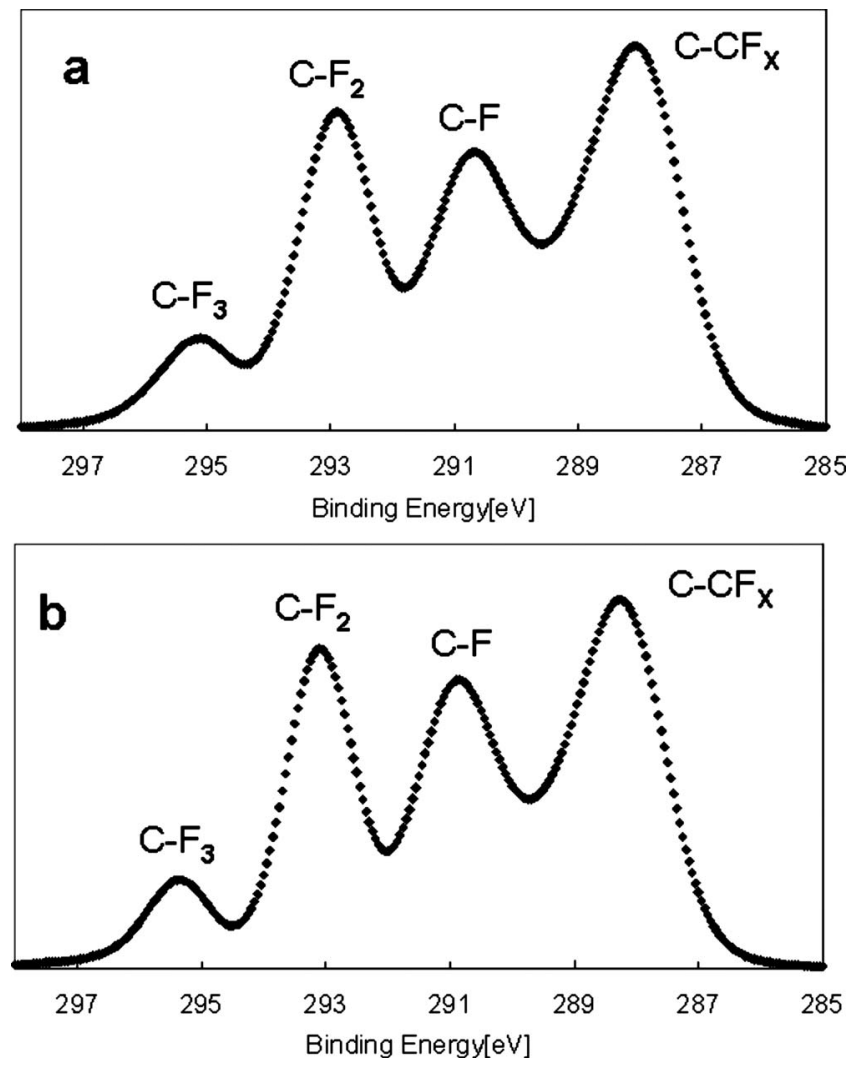

Figure 2. XPS C 1s spectra of fluorocarbon film measured at (a) take-off angles of 90 and (b) $10^{\circ}$ before immersion.

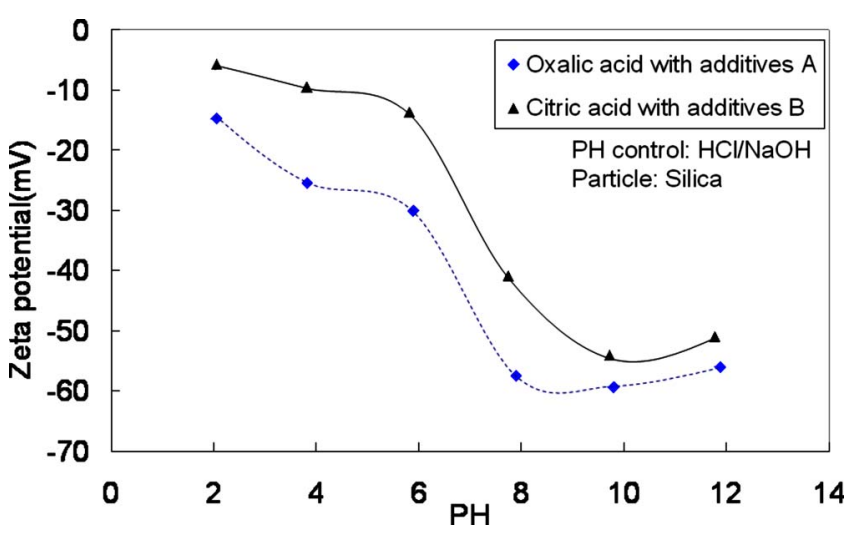

Figure 3. (Color online) Zeta-potentials of various solutions and silica particles as a function of solution $\mathrm{pH}$.

(b) $10^{\circ}$ and a photon energy of $1486.6 \mathrm{eV}$. Photoelectrons from the surface are definitely detected by low take-off angle measurement and those from bulk at high take-off measurement. In Fig. 2, four separated $\mathrm{C} 1 \mathrm{~s}$ spectra from $\mathrm{C}-\mathrm{F}_{3}, \mathrm{C}-\mathrm{F}_{2}, \mathrm{C}-\mathrm{F}, \mathrm{C}-\mathrm{CF}_{x}$, which contribute to form $\mathrm{CF}_{X}$ on the fluorocarbon film, were detected both in bulk and on the surface of the fluorocarbon film. $\mathrm{C}-\mathrm{F}_{3}$ denotes a $\mathrm{C}$ atom bonded with three $\mathrm{F}$ atoms, $\mathrm{C}-\mathrm{F}_{2}$ denotes a $\mathrm{C}$ atom bonded with two $\mathrm{F}$ atoms, $\mathrm{C}-\mathrm{F}$ denotes a $\mathrm{C}$ atom bonded with one $\mathrm{F}$ atom, and $\mathrm{C}-\mathrm{CF}_{X}$ denotes a $\mathrm{C}$ atom bonded with one $\mathrm{C}$ atom and one or two or three $\mathrm{F}$ atoms.

Oxalic acid with additives A.-Zeta-potentials of silica particles in various solutions as a function of solution $\mathrm{pH}$ is shown in Fig. 3. The $\mathrm{pH}$ is controlled by $\mathrm{HCl}$ and $\mathrm{NaOH}$. Both in alkali solution and acid solution, the zeta-potential of silica particles is charged negatively in oxalic acid with additive A solution. This means that silica particles are charged negatively even in acid solution in the oxalic acid with additive A solution. Zeta-potentials of silica particles and fluorocarbon substrate in the oxalic acid with additive A solution with $\mathrm{pH} 2.2$ were found as -48 and $-15 \mathrm{mV}$, respectively. Because both fluorocarbon substrate and silica particles indicate same negative zeta-potentials, silica particles are expected to be difficult to reabsorb on the fluorocarbon substrate and it promotes removal of silica particles from the fluorocarbon substrate. Figures $4 a$ and $b$ show particle distribution before and after brush cleaning on silicaslurry-contaminated wafers. As expected in zeta-potentials, most of the silica particles were removed successfully. Figures 5 and 6 show the $\mathrm{C}$ 1s spectra arising from $\mathrm{C}-\mathrm{F}_{3}, \mathrm{C}-\mathrm{F}_{2}, \mathrm{C}-\mathrm{F}$, and $\mathrm{C}-\mathrm{CF}_{X}$ after the oxalic acid with additives $\mathrm{A}$ immersion measured by the highresolution XPS at a take-off angle of 90 and $10^{\circ}$. Intensity at $\mathrm{C}-\mathrm{CF}_{x}$

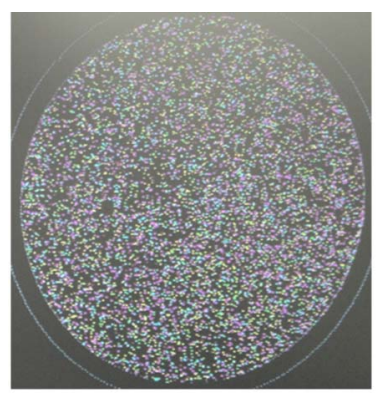

(a) Slurry contaminated wafer

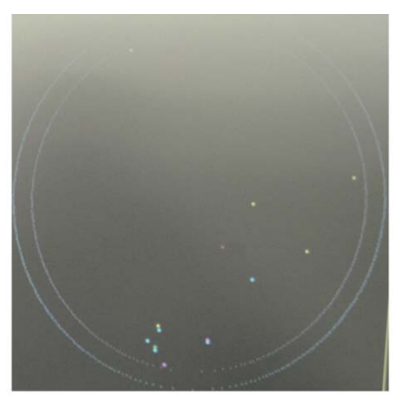

(b) After brush clean with oxalic acid with additives $A$
Figure 4. (Color online) Particle distribution on slurry-contaminated fluorocarbon wafers (a) before and (b) after brush clean with oxalic acid with additive A. 


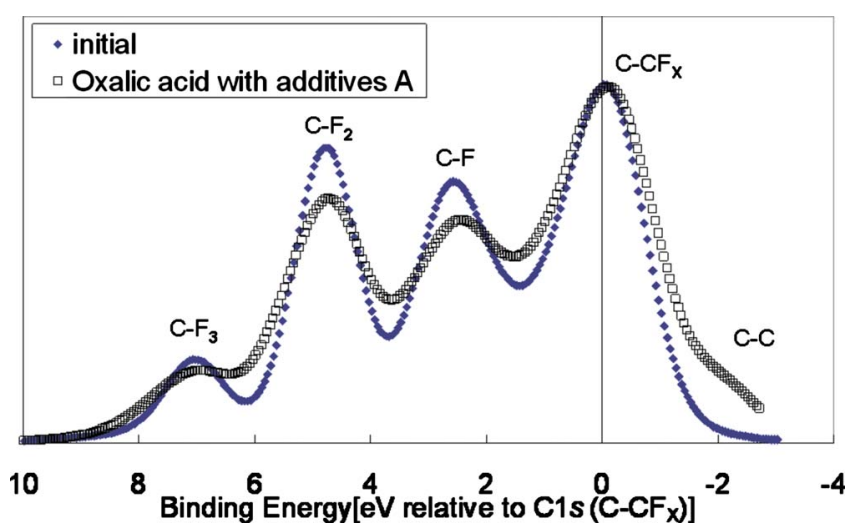

Figure 5. (Color online) C 1s spectra of fluorocarbon films measured by XPS at take-off angles of $90^{\circ}$ after oxalic acid with additive A immersion.

was normalized for comparison with intensities of different peaks. In Fig. 5 and 6, intensities at all $\mathrm{C}-\mathrm{F}_{3}$ bonds, $\mathrm{C}-\mathrm{F}_{2}$ bonds, and $\mathrm{C}-\mathrm{F}$ bonds decreased significantly. Intensity at $\mathrm{C}-\mathrm{F}_{2}$ bonds at a take-off angle of $90^{\circ}$ decreased by more than $20 \%$ from that of the initial intensity and that at a take-off angle of $10^{\circ}$ by more than $40 \%$. The full-width half maximum (fwhm) for all structures increased, and new -C-C-bonds which do not bind with $\mathrm{F}$ atoms were detected. These results reveal that the $\mathrm{C}-\mathrm{F}$ bond decomposed and $\mathrm{F}$ content became small after immersion. More change appears on the surface than that in the bulk. Two hypotheses are possible to explain why oxalic acid with additive A immersion decreased intensities of all structures of the fluorocarbon films. One is that deposition gases absorbed on fluorocarbon film desorbed during immersion, and another is the effect of the chemical structural change. The effect of residual species on the surface is qualified by TDS. Figures 7 and 8 show the TDS results of the fluorocarbon films before and after immersion, where time evolutions of relative ion intensities of the fluorocarbon series and temperature of a sample are shown. Temperature increased and was kept at $300^{\circ} \mathrm{C}$ for $5 \mathrm{~h}$ and at $400^{\circ} \mathrm{C}$ for $3 \mathrm{~h}$. No degassing of residual species was detected on the fluorocarbon film after the immersion compared with the initial, as shown in Fig. 7. As a result, chemical structural change is considered to be a reason for the decrease in intensities. Average dielectric constants measured by $C-V$ are shown in Table I. The average dielectric constant is determined from five time measurements with $5 \%$ accuracy. Average dielectric constants after immersion or brush cleaning increased by 0.1 or 0.2 , respectively. Consequently, oxalic acid with additive A cleaning generating damage to the fluorocarbon film

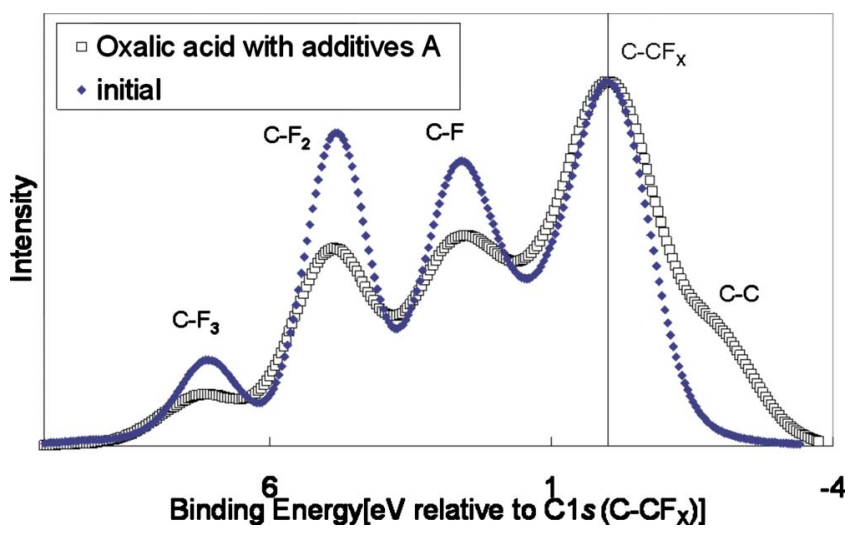

Figure 6. (Color online) C 1s spectra of fluorocarbon films measured by XPS at take-off angles of $10^{\circ}$ after oxalic acid with additive A immersion.

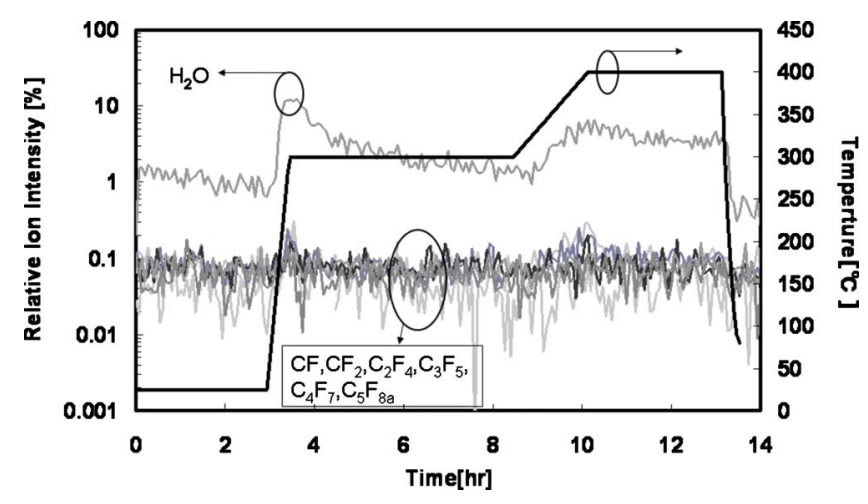

Figure 7. (Color online) Components in degassing from fluorocarbon surfaces measured by TDS before immersion.

leads to an increase, in dielectric constant, so an alternative postCMP cleaning solution for the fluorocarbon film is proposed, which is evaluated in the following section.

Citric acid with additive B.- Citric acid with additive B is considered to be an alternative to avoid degradation on fluorocarbon film. ${ }^{25}$ Zeta-potentials of silica particles in citric acid with additive B solution as a function of solution $\mathrm{pH}$ are also shown in Fig. 3. Both in alkali solution and acid solution, the zeta-potential of silica particles is charged negatively. Zeta-potentials on the fluorocarbon substrate and silica particles in citric acid with additive B solution with $\mathrm{pH} 2.2$ were found as -58 and $-15 \mathrm{eV}$, respectively. It is expected that particle removal from fluorocarbon film by citric acid with additive $\mathrm{B}$ cleaning is due to the same negative potentials. Figures $9 \mathrm{a}$ and $\mathrm{b}$ show the particle distribution before and after brush cleaning on slurry-contaminated wafers. Brush cleaning is found to remove particles as well as that in oxalic acid with additive A. The single damascene $\mathrm{Cu}$ lines after brush cleaning were observed by the optical microscope to investigate occurrence of corrosion in Fig. 10a. No corrosion on the surface of the $\mathrm{Cu}$ lines and at the interface between the $\mathrm{Cu}$ and $\mathrm{Ta}$ barrier were observed. This result reveals that no corrosion occurs in citric acid with additive $\mathrm{B}$

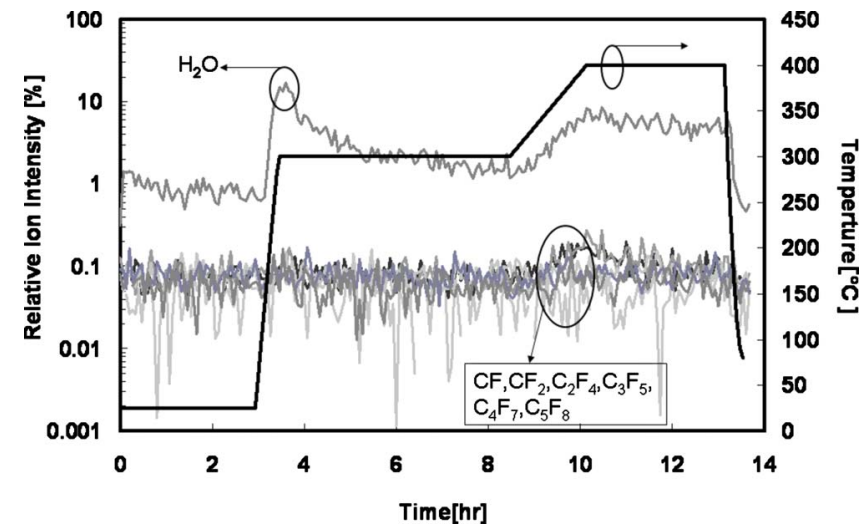

Figure 8. (Color online) Components in degassing from fluorocarbon film surfaces measured by TDS after immersion in oxalic acid with additive A.

\begin{tabular}{|c|c|}
\hline Solution & Dielectric constant \\
\hline Initial & 2.0 \\
\hline Oxalic acid with additive $\mathrm{A}$ immersion & 2.1 \\
\hline Brush clean with oxalic acid with additive A & 2.2 \\
\hline
\end{tabular}




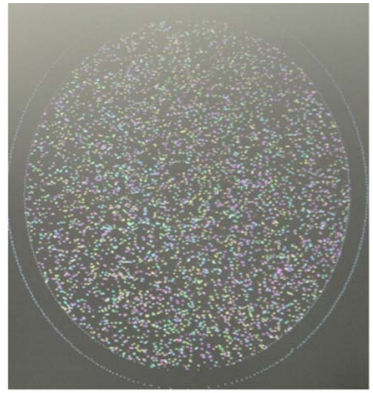

(a) Slurry contaminated wafer

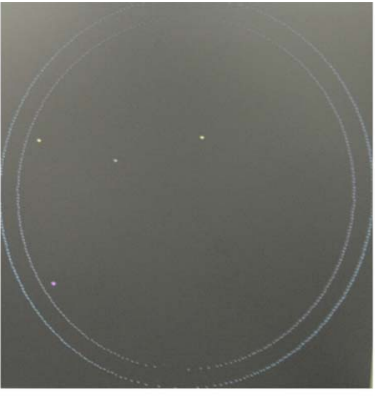

(b) After brush clean with citric acid with additives $B$
Figure 9. (Color online) Particle distribution on slurry-contaminated fluorocarbon wafers (a) before and (b) after brush clean with citric acid with additive $\mathrm{B}$.

cleaning. Etching on $\mathrm{Cu}$ films was evaluated by SEM observation in Fig. 10b. No thickness change in the $\mathrm{Cu}$ film reveals that no significant etching occurs after immersion. Figures 11 and 12 show the $\mathrm{C}$ $1 \mathrm{~s}$ spectra measured by high-resolution XPS at a take-off angle of 90 and $10^{\circ}$ after immersion. Unlike results after oxalic acid with additive A shown in Fig. 5 and 6, neither decrease in spectral intensities

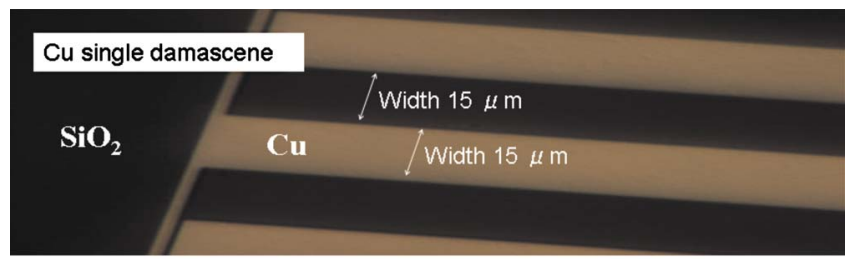

(a)

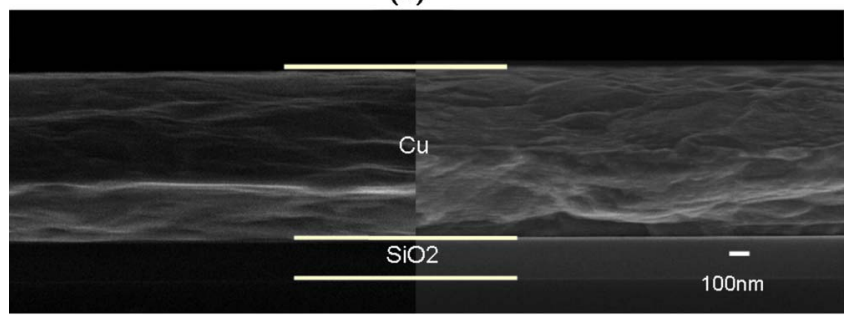

(b) Initial

(C) After cleaning

Figure 10. (Color online) (a) Corrosion evaluation by an optical microscopy bird's-eye view on $\mathrm{Cu}$ films and (b) etching evaluation by an SEM crosssectional view on $\mathrm{Cu}$ films after citric acid with additive $\mathrm{B}$ immersion.

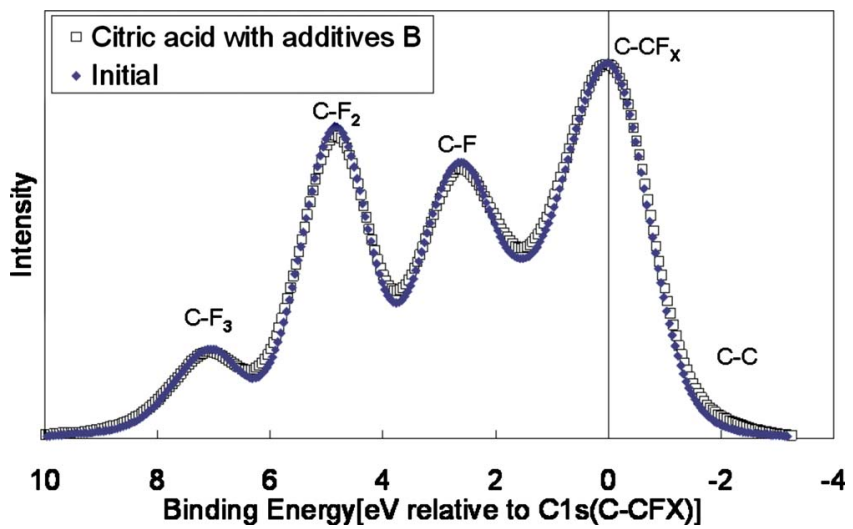

Figure 11. (Color online) XPS C 1s spectrum of fluorocarbon films measured at take-off angles of $90^{\circ}$ after immersion in citric acid with additive $\mathrm{B}$.

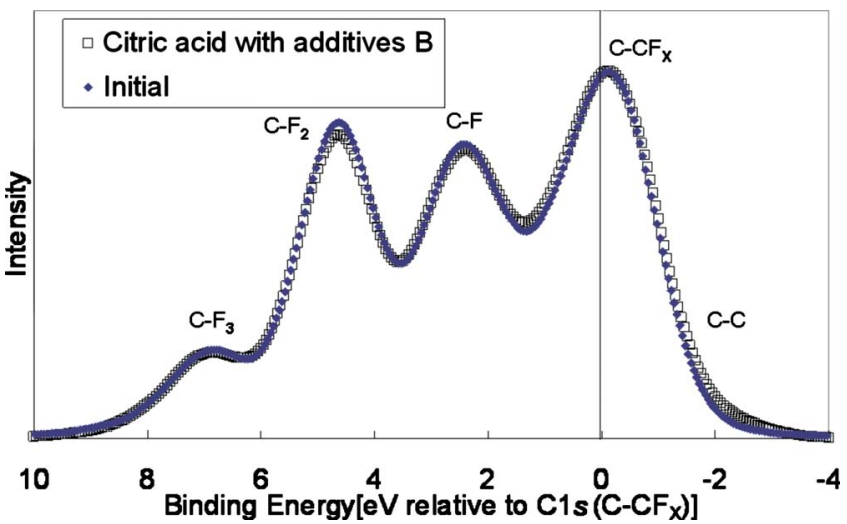

Figure 12. (Color online) XPS C 1s spectrum of fluorocarbon films measured at take-off angles of $10^{\circ}$ after immersion in citric acid with additive B.

from $\mathrm{C}-\mathrm{F}_{3}$ bonds, $\mathrm{C}-\mathrm{F}_{2}$ bonds, and $\mathrm{C}-\mathrm{F}$ bonds, nor change of the fwhm of all structures was found, and no new-C-C-bonds were observed. Average dielectric constants after immersion and brush cleaning are summarized in Table II. Dielectric constants after citric acid with additive $B$ cleaning remained at almost the same value. This indicates that because there is no change of chemical structure and dielectric constant, citric acid with additive $\mathrm{B}$ can be applied in post-CMP cleaning applications on fluorocarbon films.

Effects of additives. - Oxalic acid and citric acid without additives were prepared to demonstrate the effect of additives. The $\mathrm{C} 1 \mathrm{~s}$ spectra of the fluorocarbon film by high-resolution XPS at a take-off angle of 90 and $10^{\circ}$ after immersion are shown in Fig. 13-16. Compared to the spectra before immersion, no degradation of intensities was detected. Results of dielectric constants after immersion are summarized in Table III. No changes in chemical structure or average dielectric constant values were observed by high-resolution XPS or $C$ - $V$ measurement, respectively.

Table II. Dielectric constants of the fluorocarbon films before and after citric acid cleaning with additive $B$.

Solution

Dielectric constant

Initial

Citric acid additive B immersion

Brush clean with citric acid with additive B

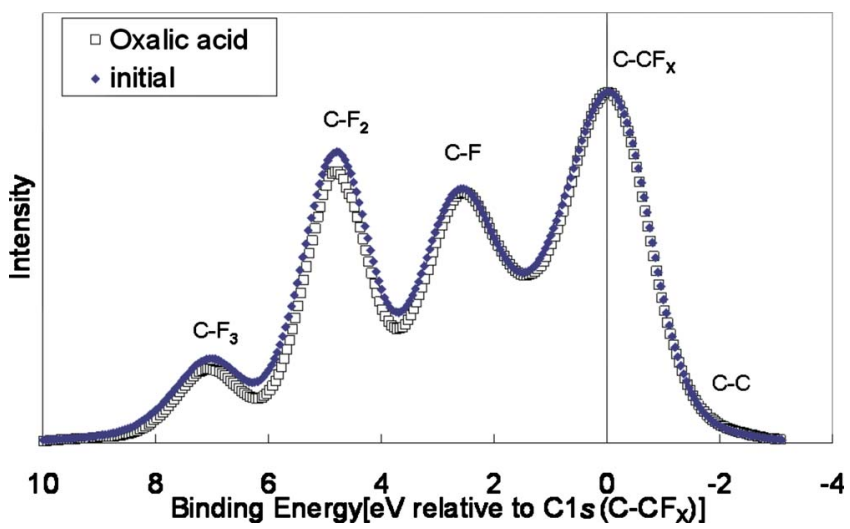

Figure 13. (Color online) $\mathrm{C} 1 \mathrm{~s}$ spectrum of fluorocarbon films measured by XPS at take-off angles of $90^{\circ}$ after immersion in oxalic acid without additives. 


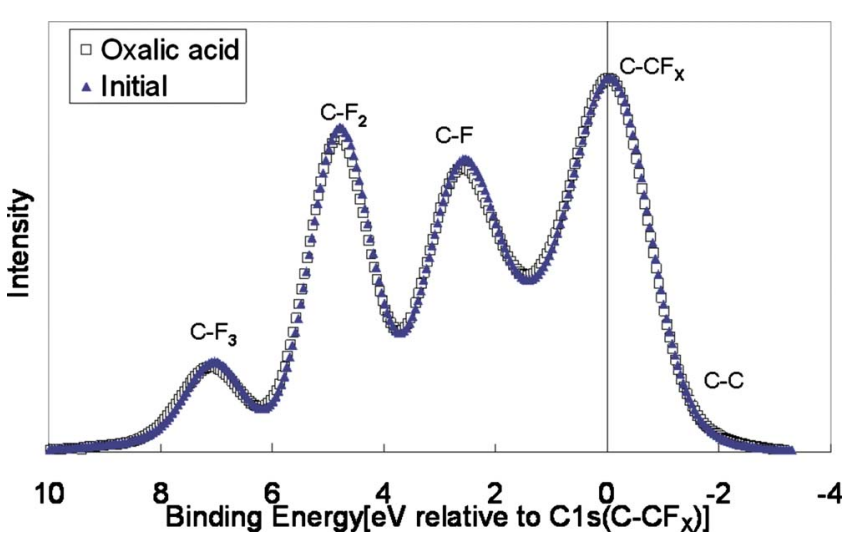

Figure 14. (Color online) C 1s spectrum of fluorocarbon films measured by XPS at take-off angles of $10^{\circ}$ after immersion in oxalic acid without additives.

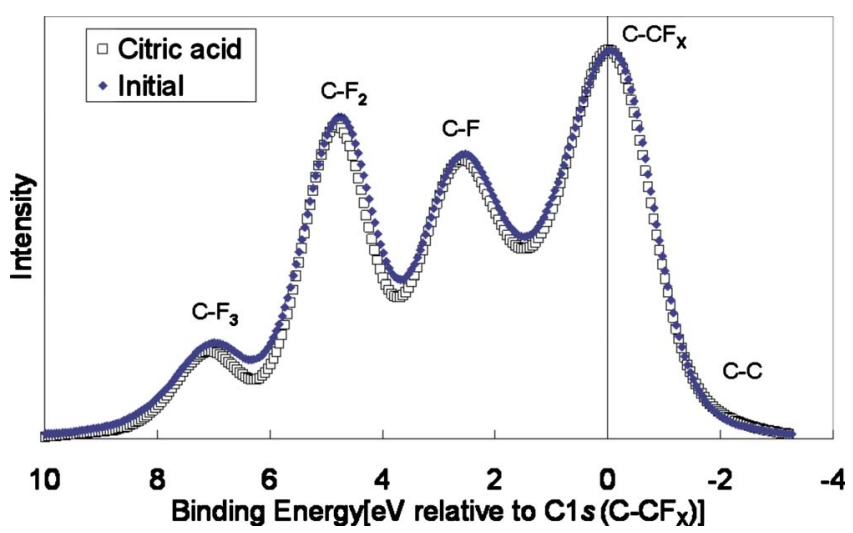

Figure 15. (Color online) C 1s spectrum of fluorocarbon films measured by XPS at take-off angles of $90^{\circ}$ after immersion in citric acid without additives.

The effects of type of additives and acid chemicals on the chemical structure and dielectric constant are summarized in Table IV. While only oxalic acid with additive A shows a significant change in $\mathrm{C}-\mathrm{F}_{2}$ bond intensity and the $\mathrm{C}-\mathrm{F}$ bond fwhm increases by more than $20 \%$ and there is an increase in dielectric constant, no change of spectra and dielectric constant were observed in other combinations. Consequently, additive $\mathrm{A}$ is considered to play an important role in degrading the chemical structure and dielectric constants.

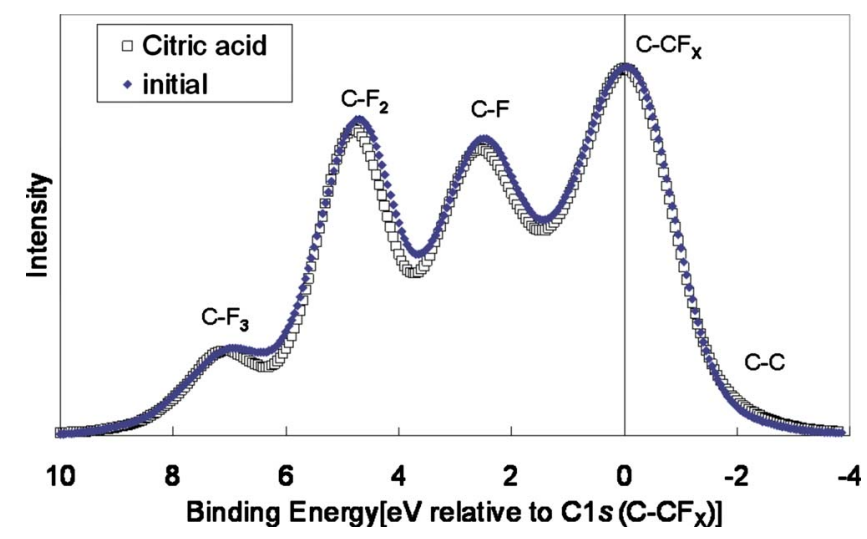

Figure 16. (Color online) C 1s spectrum of fluorocarbon film measured by XPS at take-off angles of $10^{\circ}$ after citric acid immersion without additives.

\begin{tabular}{|c|c|}
\hline Solution & Dielectric constant \\
\hline Initial & 2.0 \\
\hline Oxalic acid without additives & 2.0 \\
\hline Citric acid without additives & 2.0 \\
\hline
\end{tabular}

Additives are considered as necessary components in post-CMP cleaning. ${ }^{20}$ Corrosion on $\mathrm{Cu}$ was observed by the optical microscope after (a) oxalic acid without additive and (b) citric acid without additive immersion for $30 \mathrm{~min}$, as shown in Fig. 17. The roughness of the $\mathrm{Cu}$ surface is considerably increased and corrosion is observed in both solutions. Etching on $\mathrm{Cu}$ films was evaluated by SEM observation in Fig. 18 (a) before immersion, (b) after immersion into oxalic acid with additive $\mathrm{A}$ for $1 \mathrm{~h}$, and (c) in oxalic acid without additive for $1 \mathrm{~h}$. The thickness of the $\mathrm{Cu}$ film decreased after immersion in oxalic acid without additive, as shown in Fig. 18c, while no change of $\mathrm{Cu}$ film thickness was observed after immersion into oxalic acid with additive $\mathrm{A}$, as shown in Fig. 18b. These results reveal that the $\mathrm{Cu}$ corrosion inhibitor is considered necessary to avoid corrosion. Zeta-potentials on the fluorocarbon substrate and silica particles in solutions without additives with $\mathrm{pH} 2.2$ were +10 and $-15 \mathrm{eV}$, respectively. Because the fluorocarbon substrate and silica particles indicate different zeta-potentials, it should prevent removal of silica particles from the fluorocarbon substrate. The contact angles of a droplet of different solutions dropped on the fluorocarbon surface are summarized in Table V. The contact angle of a drop of ultra pure water (UPW) dropped on the fluorocarbon surface was $100^{\circ}$. No significant change of contact angles was observed in a drop of oxalic acid or citric acid without additives. Contact angles of a drop of oxalic acid with additive $A$ or the citric acid with additive $\mathrm{B}$ dropped decreased to 46 and $52^{\circ}$, respectively. No significant change was observed for the contact angles of drops of all acid solutions and UPW dropped on $\mathrm{SiO}_{2}$. These results reveal that additives $\mathrm{A}$ and $\mathrm{B}$ improve wettability, and this results in good particle removal on the fluorocarbon film. ${ }^{26,20}$ Figures $19 a$ and $b$ show particle distribution (a) after brush cleaning in oxalic acid without additive $\mathrm{A}$ and (b) with additive A on slurry contaminated fluorocarbon wafers at the same brush conditions. Brush cleaning in oxalic acid without additive A did not remove particles as well as that in oxalic acid with additive A. Therefore, it is important to choose appropriate additives in post-CMP cleaning solutions, especially new dielectric materials such as nonporous low- $k$ fluorocarbon films.

\section{Conclusions}

The post-CMP clean solutions for advanced nonporous ultralow- $k$ dielectric, fluorocarbon film were evaluated by using the high-resolution XPS and $C-V$ measurement. Citric acid with additive $\mathrm{B}$ is considered to be an appropriate post-CMP cleaning solution to avoid degradation on fluorocarbon films, while decrease in fluorine content measured by the high-resolution XPS and an increase in dielectric constant were observed after oxalic acid clearing with another additives. Additives are considered to play an important role in changing the chemical structures and dielectric constants for nonporous fluorocarbon films. To complete successful integration of post-CMP cleaning on new dielectric materials such as nonporous low- $k$ fluorocarbon films, appropriate solutions and additives should be carefully selected to avoid electrical degradation in subsequent processes. Efficient best use of additives in post-CMP cleaning solution is very important to achieve ultraclean surfaces after CMP polishing. More experiments and investigations should be carried out for a complete understanding of the effects of additives. 
Table IV. Change of fluorocarbon structure and dielectric constants measured by XPS and $C-V$.

\begin{tabular}{|c|c|c|c|c|c|c|}
\hline \multirow[b]{2}{*}{ Solution } & \multirow[b]{2}{*}{ Additives } & \multicolumn{2}{|c|}{ Change of $\mathrm{C}-\mathrm{F}_{2}$ intensity (\%) } & \multicolumn{2}{|c|}{ Change of C-F fwhm (\%) } & \multirow{2}{*}{$\begin{array}{c}\text { Change of } \\
\text { dielectric constants }\end{array}$} \\
\hline & & Take-off $90^{\circ}$ & Take-off $10^{\circ}$ & Take-off $90^{\circ}$ & Take-off $10^{\circ}$ & \\
\hline Oxalic & A & -21 & -40 & 34 & 21 & 0.2 \\
\hline Citric & $\mathrm{B}$ & -4 & -7 & 0 & 3 & 0 \\
\hline Oxalic & Without & -6 & -2 & -5 & 0 & 0 \\
\hline Citric & Without & -2 & -1 & 0 & 2 & 0 \\
\hline
\end{tabular}
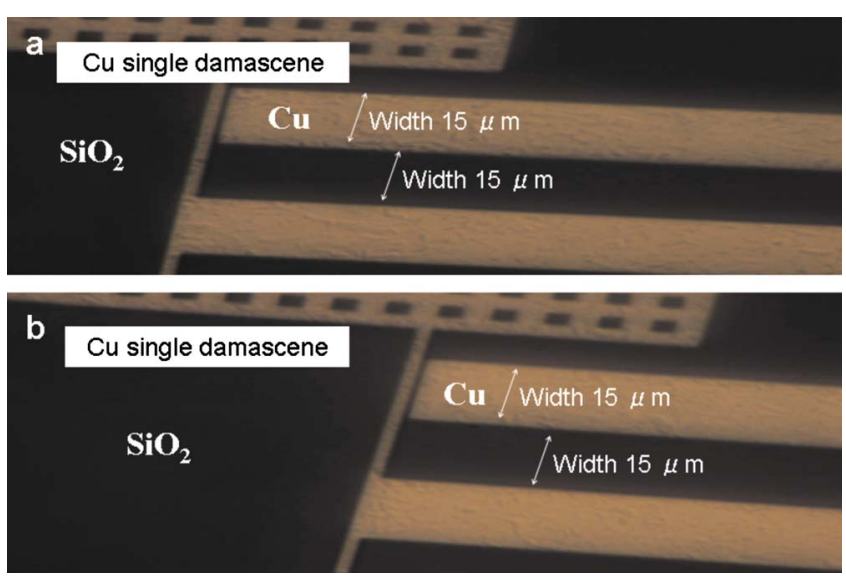

Figure 17. (Color online) Corrosion evaluation by optical microscopy bird's-eye view on $\mathrm{Cu}$ film after (a) oxalic acid without additive and (b) citric acid without additive immersion.

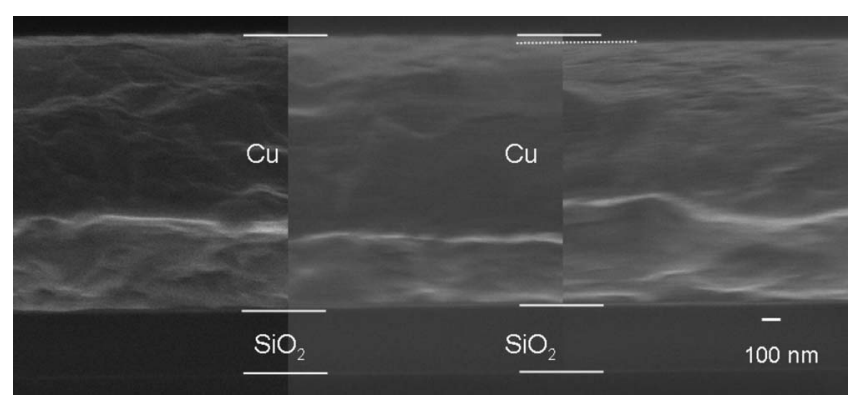

Figure 18. Etching evaluation by SEM cross-sectional view on $\mathrm{Cu}$ film (a) before immersion, (b) after oxalic acid with additive A immersion, and (c) oxalic acid without additive immersion for $1 \mathrm{~h}$.

Table V. Contact angles of the fluorocarbon and $\mathrm{SiO}_{2}$ surfaces with various cleaning solutions and UPW.

\begin{tabular}{lcc} 
& \multicolumn{2}{c}{ Contact angle $\left(^{\circ}\right)$} \\
\cline { 2 - 3 } Droplet solutions & Fluorocarbon & $\mathrm{SiO}_{2}$ \\
\hline UPW & 100 & 14 \\
Oxalic acid with additive A & 46 & 23 \\
Citric acid with additive B & 52 & 7 \\
Oxalic acid & 96 & 20 \\
Citric acid & 98 & 16
\end{tabular}

\section{Acknowledgments}

The authors express great thanks for the technical assistance of Dr. Tomoyuki Suwa, Atsutoshi Inokuchi, and Hidekazu Ishii of the

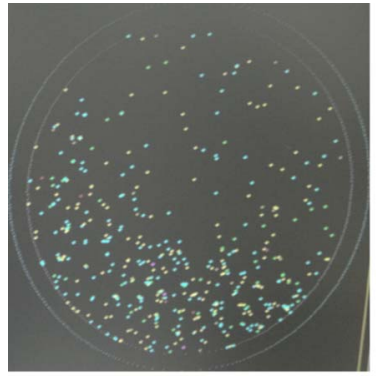

(a) After brush clean with oxalic acid without additives $A$

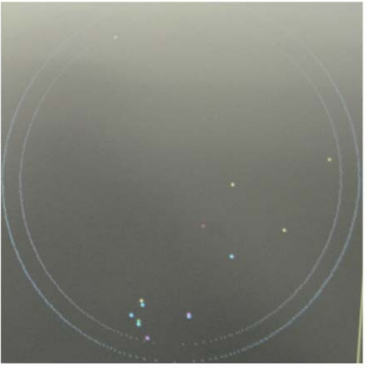

(b) After brush clean with oxalic acid with additives $A$
Figure 19. (Color online) Particle distribution on slurry-contaminated fluorocarbon wafers after (a) a brush cleaning with oxalic acid with additive A and (b) a brush cleaning with oxalic acid without additive A.

New Industry Creation Hatchery Center (NICHe) of Tohoku University. X.G. also expresses great thanks for financial assistance from the Realize Advanced Technology Corporation. ticle.

Tohoku University assisted in meeting the publication costs of this ar-

\section{References}

1. M. Fayolle, G. Passemard, O. Louveau, F. Fusalba, and J. Cluzel, Microelectron Eng., 70, 255 (2003)

2. S. Kondo, K. Fukaya, K. Yamada, T. Miyazaki, M. Fujita, D. Abe, S. Kunisaki, T. Enomoto, and S. Tominaga, Microelectron. Eng., 84, 2615 (2007).

3. T. Yoda, K. Fujita, H. Miyajima, R. Nakata, N. Miyashita, and N. Hayasaka, J. Phys. D: Appl. Phys., 443872 (2005).

4. N. Hata, C. Negoro, S. Takada, X. Xiao, K. Yamada, and T. Kikkawa, in Proceedings of the International Interconnects Technology Conference, IEEE, p. 51 (2003)

5. T. Yoda, Y. Nakasaki, H. Hashimoto, K. Fujita, H. Miyajima, M. Shimada, R. Nakata, N. Kaji, and N. Hayasaka, Jpn. J. Appl. Phys., Part 1, 44, 75 (2005).

6. M. R. Baklanov, Q. T. Le, E. Kesters, F. Iacopi, J. Van Aelst, H. Struyf, W. Boullart, S. Vanhaelemeersch, and K. Maex, in Proceedings of the International Interconnects Technology Conference, IEEE, p. 10.1 (2004).

7. B. U. Yoon, S. Kondo, S. Tokitoh, A. Namiki, K. Misawa, K. Inukai, N. Ohashi, and N. Kobayashi, p. 13.3, in Proceedings of the International Interconnects Technology Conference, IEEE, p. 13.3 (2004)

8. M. Kodera, S. Uekusa, H. Nagano, K. Tokushige, S. Shima, A. Fukunaga, Y Mochizuki, H. Hiyama, and M. Tsujimura, Abstract 914, Vol. 2004-2, The Electrochemical Society Meeting Abstracts, Honolulu, HI, Oct 3-8, 2004 (2004).

9. C. Goldberg, L. Mercade, S. Filipiak, and S. Crown, in Proceedings of the International Interconnects Technology Conference, IEEE, p. 209 (2002).

10. G. Kloster, T. Scherban, G. Xu, J. Blaine, B. Sun, and Y. Zhou, in Proceedings of the International Interconnects Technology Conference, IEEE, p. 242 (2002)

11. K. A. Reinhardt, Handbook of Silicon Wafer Cleaning Technology, 2nd ed., p. 257, William Andrew, NY (2008).

12. A. Ishikawa, Y. Shishida, T. Yamanishi, N. Hata, T. Nakayama, N. Fujii, H. Tanaka, H. Matsuo, K. Kinoshita, and T. Kikkawa, J. Electrochem. Soc., 153, 692 (2006).

13. T. Ohmi, M. Hirayama, and A. Teramoto, J. Phys. D: Appl. Phys., 39, 1 (2006).

14. T. Ohmi, M. Hirayama, Y. Shirai, A. Teramoto, W. Cheng, and A. Inokuchi, SEAJ Journal, 2006, 101 (in Japanese).

15. A. Itoh, A. Inokuchi, S. Yasuda, A. Teramoto, T. Goto, M. Hirayama, and T. Ohmi, J. Phys. D: Appl. Phys., 47, 2515 (2008).

16. H. Tanaka, Z. Chuanjie, Y. Hayakawa, M. Hirayama, A. Teramoto, S. Sugawa, and T. Ohmi, Jpn. J. Appl. Phys., Part 1, 42, 1911 (2003).

17. T. Goto, M. Hirayama, H. Yamauchi, M. Moriguchi, S. Sugawa, and T. Ohmi, Jpn J. Appl. Phys., Part 1, 42, 1887 (2003).

18. T. Goto, H. Yamauchi, T. Kato, M. Terasaki, A. Teramoto, M. Hirayama, S Sugawa, and T. Ohmi, Jpn. J. Appl. Phys., Part 1, 43, 1784 (2004). 
19. T. Nemoto, H. Imai, A. Teramoto, T. Ito, S. Sugawa, and T. Ohmi, J. Electrochem. Soc., 155, 323 (2008)

20. T. Ohmi, Scientific Wet Process Technology for Innovative LSI/FPD Manufacturing, p. 118, Taylor \& Francis, London (2006).

21. Y. Li, Microelectronic Applications of Chemical Mechanical Planarization, p. 249, Wiley Interscience, New York (2007).

22. U. Gelius, B. Wannberg, P. Baltzer, H. Fellner-Feldegg, G. Carlsson, C. G. Johansson, J. Larsson, P. Munger, and G. Vergerfos, J. Electron Spectrosc. Relat. Phenom., 52, 747 (1990).
23. T. Ohmi, Scientific Wet Process Technology for Innovative LSI/FPD Manufacturing, p. 51, Taylor \& Francis, London (2006).

24. T. Nozawa, T. Nishizuka, Y. Kobayashi, M. Hirayama, and T. Ohmi, Abstracts of the 18th Symposium on Plasma Science for Materials, JSPS, p. 2 (2005).

25. X. Gu, T. Nemoto, A. Teramoto, R. Hasebe, T. Ito, and T. Ohmi, Abstracts of the 9th International Symposium on Ultra Clean Processing of Semiconductor Surface, Imec, p. 112 (2008).

26. M. Miyamoto, S. Hirano, H. Chibahara, T. Watadani, M. Akazawa, and S. Furukawa, Jpn. J. Appl. Phys., Part 1, 45, 7637 (2006). 